\title{
Spray and Combustion Characteristics of a Novel Multi-circular Jet Plate in Air-assisted Atomizer
}

\author{
Shahrin Hisham Amirnordin ${ }^{1, *}$, Amir Khalid ${ }^{1,2}$, David Igram Patrick ${ }^{1}$, Mohd Faizal \\ Mohideen Batcha ${ }^{1}$, and Mas Fawzi Mohd Ali ${ }^{1}$ \\ ${ }^{1}$ Centre for Energy and Industrial Environment Studies (CEIES), Faculty of Mechanical and \\ Manufacturing Engineering, Universiti Tun Hussein Onn Malaysia, 86400 Parit Raja, Batu Pahat, \\ Johor, Malaysia. \\ ${ }^{2}$ Advanced Technology Centre (ATC), Faculty of Engineering Technology, Universiti Tun Hussein \\ Onn Malaysia, 86400 Parit Raja, Batu Pahat, Johor, Malaysia.
}

\begin{abstract}
Atomization of liquid fuel in air-assisted atomizer is highly dependent on air mixing, which can be enhanced using turbulent generators, such as multi-circular jet (MCJ) plates and swirler. This study aims to determine the effects of novel MCJ plates on the spray and combustion characteristics of an air-assisted atomizer by evaluating spray and flame parameters, such as penetration length, cone angle, and cone area. MCJ 30 and MCJ 45 , with inclined jets at $30^{\circ}$ and $45^{\circ}$, respectively, were used in the experiment. A swirler was also used for comparison. The spray and flame images were recorded at different equivalence ratios through direct photography and analyzed using image J software. Flame temperature was determined using a thermal infrared camera, and burning chamber and flue gas temperatures were measured using thermocouples. The spray and flame characteristics of MCJ 30 exhibited performance comparable with those of the MCJ 45 and swirler. The integration of turbulence and swirling motion concept into the novel MCJ plates can enhance the mixing formation and thus improve the performance of burner combustion.
\end{abstract}

\section{Introduction}

Atomization is a process in which liquid fuel is converted from its bulk form into spray droplets and other physical dispersion of small particles in a gaseous environment through an atomizer. Atomization is important in combustion because most combustion systems, such as internal combustion engines and industrial furnace, work on fuel that should be

\footnotetext{
*Corresponding author : shahrin@uthm.edu.my
} 
atomized prior to use. Spray quality and liquid distribution influence combustion efficiency, stability and pollution emissions, and increase the rate of heat and mass transfer $[1,2]$. Atomization and spray formation can be characterized considering the improvements in measurement and instrumentation techniques. Spray characteristics can be categorized into macroscopic characteristics, including penetration, cone angle, radial dispersion, and axial velocity, and microscopic characteristics, including droplet diameter and distribution [3]. In addition, spray characteristics are affected by factors, such as pressure, atomizer geometry, gas to liquid ratio (GLR), fluid density, and viscosity [4]. Several studies [3, 5, 6] reported that spray penetration length is considerably affected by pressure supplied to the spray; moreover, the thermo-physical properties of the liquid do not control the spray characteristics. Khalid et al. [7] evaluated spray characteristics by using water-emulsified diesel fuel with various water percentages and indicated that increasing the quantity of water decreases the fuel viscosity, leading to high spray penetration. Khalid et al. [8] found that jatropha oil exhibits higher levels of spray penetration than diesel fuel [8]. Another study revealed that the spray cone angle increases due to high viscosity level and surface tension of the fluid $[9,10]$. Moreover, the use of a swirler in an atomizer can significantly increase the spray cone angle and decrease the GLR $[1,4,9,11]$.

Atomizer geometry determines the spray characteristics and mixing effect on combustion [2]. Atomizer plates, such as fractal and swirl plates, possess different geometries and generate different motions of fluid inside the mixing chamber in an atomizer unit. Swirl plate is an atomizer commonly used in internal combustion and aeroengines. A simplex nozzle possesses a swirl chamber, which forces the liquid to leave the nozzle as an annular sheet. The sheet spreads out radially through a circular orifice and forms a hollow cone spray of finite film thickness [9]. Particularly, swirl flow exhibits potential to extend the residence time and enhances flow mixing by rotational movement of the flow field [12]. Swirling the mixture significantly increases the spray cone angle. However, secondary air beyond the exit orifice does not improve the spray characteristics but induces an undesirable contact between the liquid and the exit port [11-13].

Turbulent premixed flames are of great importance for technical combustion system because they exhibit high power density and low pollutant emission. Grids, such as perforated plates, are used for non-swirl stabilized flames to produce a certain level of standard turbulence $[14,15]$. To generate turbulence in axisymmetric tubes, two approaches were available, namely, passive and active techniques. Passive approaches involve highvelocity streams and jet issuing into a mainstream, while active approaches involve oscillating grids, such as fractal grids. Fractal grids are a new type of low-blockage turbulence generator. Previous research found that fractal grids produce intense turbulence over a long range of streamwise distances. The frame brush thickness, flame angle, and turbulence burning increase with increasing turbulence level of the flow [16-19]. Fractalshaped orifice also significantly affects pressure drop; that is, the pressure drop measured across the fractal-shape orifice is lower than that of the regular circular orifices from the same flow area [20,21].

In this study, the effects of plate geometry on the spray and combustion characteristics of an air-assisted atomizer were investigated. An experiment was conducted in a burning chamber system through direct photography and thermal imaging. 


\section{Experimental Setup}

An atomizer was equipped with an air compressor to supply primary air at the required pressure. A fuel pump was used to supply diesel to the atomizer and was controlled by the Ono Sokki mass flow meter. The schematic of the experiment is shown in Figure 1. The properties of diesel are presented in Table 1, and the experimental conditions are shown in Table 2.

Spray and flame videos were recorded using digital single-lens reflex camera Nikon D90. GOM player was used to obtain still images, and Image J was used for image processing. Flame temperature was recorded using thermal infrared (IR) camera FLIR T640. Flue gas and burning chamber temperatures were measured by K-type thermocouples, which were placed inside the chimney and burning chamber, respectively. Secondary air (from blower Hitachi RB40VA) was supplied into the atomizer to complete the combustion.

Diesel was sprayed via eight nozzles of the atomizer with a diameter of $1 \mathrm{~mm}$ by using three different plate geometries as turbulence generator in the premix chamber. Both plates were drilled with eight holes of $2 \mathrm{~mm}$ diameter at different angles, namely, $30^{\circ}$ (MCJ 30) and $45^{\circ}$ (MCJ 45). Both MCJ 30 and MCJ 45 (Figure 2) were introduced with a plate design that integrates the turbulence and swirl concept of fuel air mixing inside the premix chamber. The characteristics of both MCJ plates were compared with those of a swirler, a commercial turbulence generator. Figure 3 shows the actual images of the MCJ plates and the swirler used in the study. The parameters of spray, flame, and temperature are shown in Figure 4.

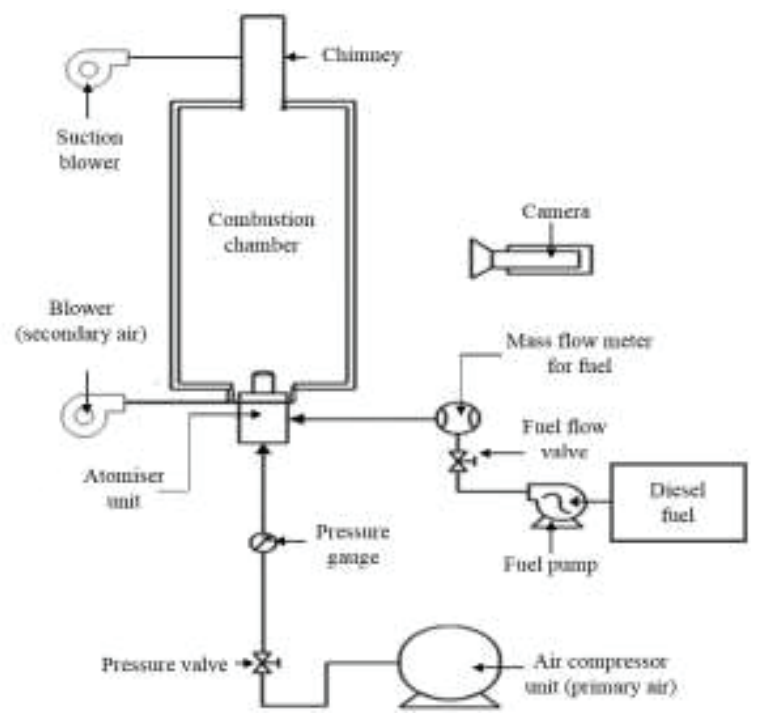

Fig. 1. Schematic diagram of experimental setup. 
Table 1. Properties of diesel fuel (No. 2).

\begin{tabular}{lcc}
\hline \multicolumn{1}{c}{ Property } & Unit & Value \\
\hline Density at $30^{\circ} \mathrm{C}$ & $\mathrm{kg} / \mathrm{m}^{3}$ & 0.8420 \\
\hline Flash point, minimum & ${ }^{\circ} \mathrm{C}$ & 52 \\
\hline Cetane number, minimum & & 40 \\
\hline $\begin{array}{l}\text { Kinematic viscosity } 40^{\circ} \mathrm{C}, \\
\text { maximum }\end{array}$ & $\mathrm{mm}^{2} / \mathrm{sec}$ & 4.1 \\
\hline
\end{tabular}

Table 2. Operating conditions.

\begin{tabular}{|c|c|}
\hline Air pressure, $\mathrm{MPa}$ & 0.1 \\
\hline Air density, $\mathrm{kg} / \mathrm{m}^{3}$ & 1.1770 \\
\hline Ambient temperature, $\mathrm{K}$ & 300 \\
\hline & \\
Equivalence ratio & $0.4-1.6$ \\
\hline
\end{tabular}

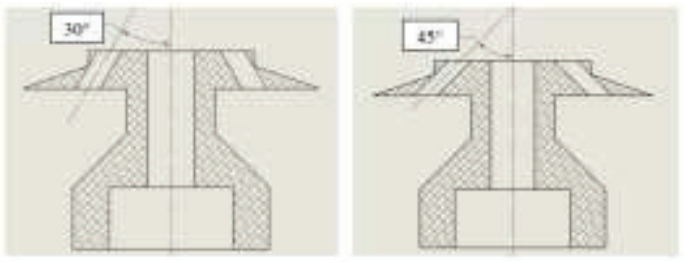

Fig. 2. Cross sectional area of MCJ 30 and MCJ 45.

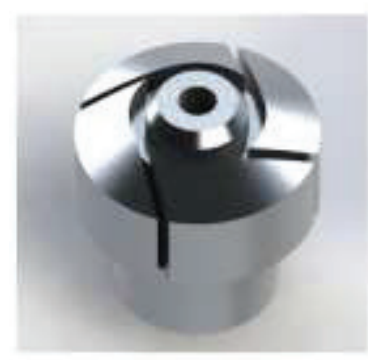

(a) Swirler

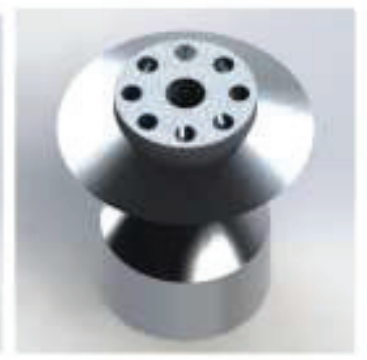

(b) $\mathrm{MCJ} 30$

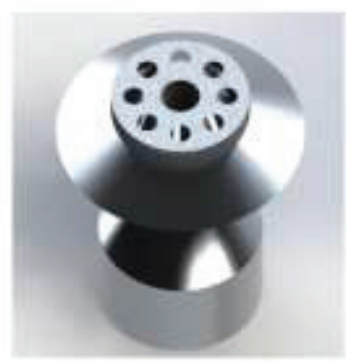

(c) MCJ 45

Fig. 3. Turbulence generators. 


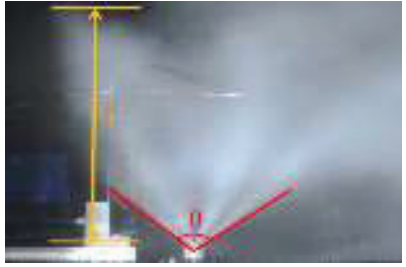

(a)

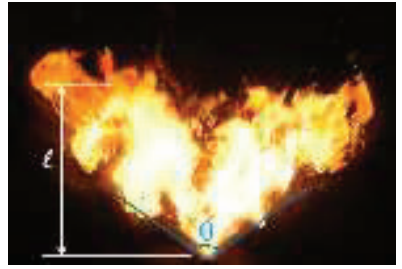

(b)

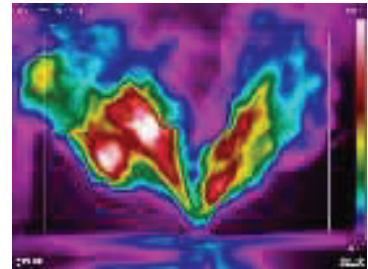

(c)

Fig. 4. Parameters of (a) spray (b) flame and (c) temperature profile.

\section{Results and discussion}

This section describes the effects of different plates on the spray and flame characteristics of the air-assisted atomizer. Figure 5 shows the spray, flame, and thermal images acquired from three different types of plates at 1.0 equivalence ratio.

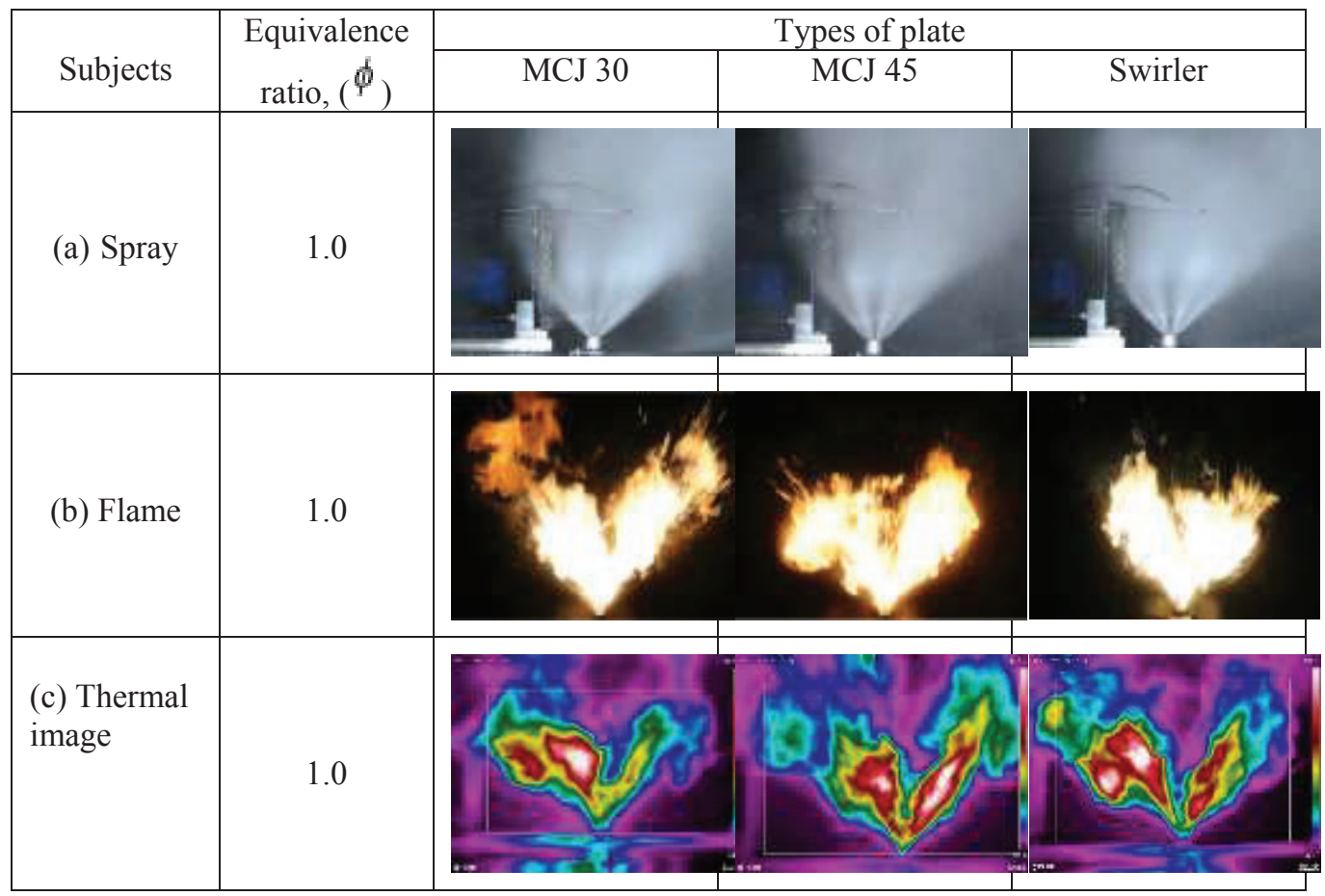

Fig. 5. Images of (a) spray (b) flame and (c) thermal at 1.0 equivalence ratio.

Figure 6(a) illustrates the spray penetration, spray cone angle, and spray area at different equivalence ratios. MCJ 30 produces the longest spray penetration (from $194 \mathrm{~mm}$ to $238 \mathrm{~mm}$ ) compared with MCJ 45 (from $179 \mathrm{~mm}$ to $220 \mathrm{~mm}$ ) and the swirler (from 173 $\mathrm{mm}$ to 211 ). MCJ 45 also exhibits the largest spray cone angle, followed by the swirler and 
MCJ 30. Meanwhile, the swirler generates the smallest spray area $\left(46,296 \mathrm{~mm}^{2}\right)$ compared with MCJ 30 and MCJ 45 (50,268 and 47,090 $\mathrm{mm}^{2}$, respectively) at 0.4 equivalence ratio. As the equivalence ratio increases from 0.4 to 1.4 , the spray penetration, spray cone angle, and spray area of all the plates also increase. Compared with MCJ 45 and the swirler, MCJ 30 exhibits better performance due to its $30^{\circ}$ jet angle, which promotes higher mixing rate in the premix chamber and lower pressure losses [4].

Figure 6(b) shows the flame length, flame cone angle, and flame area against the equivalence ratios. Flame length and area are the highest in MCJ 30, followed by MCJ 45 and swirler. However, MCJ 45 generates the smallest flame cone angle, which increases gradually from $89^{\circ}$ to $110^{\circ}$, whereas MCJ 45 and swirler produce wider spare cone areas at $100^{\circ}$ to $115^{\circ}$ and $102^{\circ}$ to $113^{\circ}$, respectively. A misfire is detected in the swirler at $\varnothing=0.4$. This result is in line with the spray characteristics shown in Figure 6 and is related to the geometrical advantages of the $30^{\circ}$ jet angle in fuel air mixing [12].

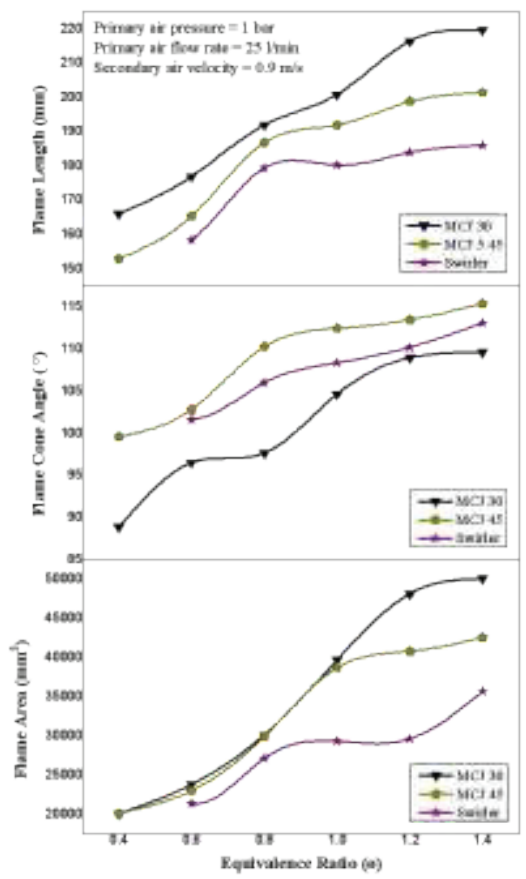

(a)

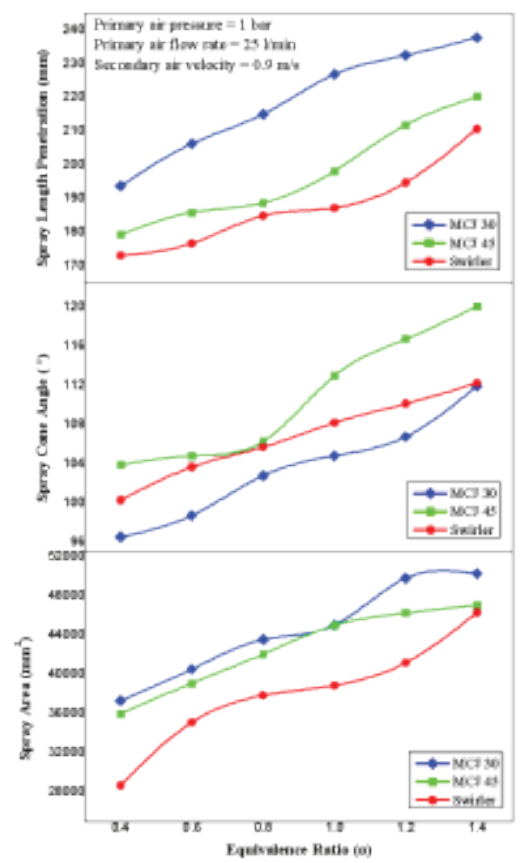

(b)

Fig. 6. (a) Spray and (b) flame characteristics of three plates at different equivalence ratio.

In this study, temperature measurements were conducted using the thermal images of the flame. Data were collected from the K-type thermocouple and recorded using data logger. Figure 7 displays the maximum temperature of the flame and the temperatures of the burning chamber and flue gas. All the temperatures increase significantly with increasing equivalence ratio. High quantities of fuel and air mixtures were introduced into the atomizer at high equivalence ratios. Large spray and flame were created by the 
atomizer, resulting in increased temperatures of flame, burning chamber, and flue gas. These findings are consistent with those presented in Figure 6. Among all the plates, MCJ 30 exhibits the highest flame and flue gas temperatures, and MCJ 45 displays the highest temperature in the burning chamber. The high burning chamber temperature could be due to the high flame angle, which is closer to the thermocouple located at the center of the chamber [12]. Overall results show that MCJ 30 exhibits the highest performance for spray and combustion compared with MCJ 45 and swirler. The novel geometry of MCJ 30 not only produces high combustion temperature but also contributes to flame stability.

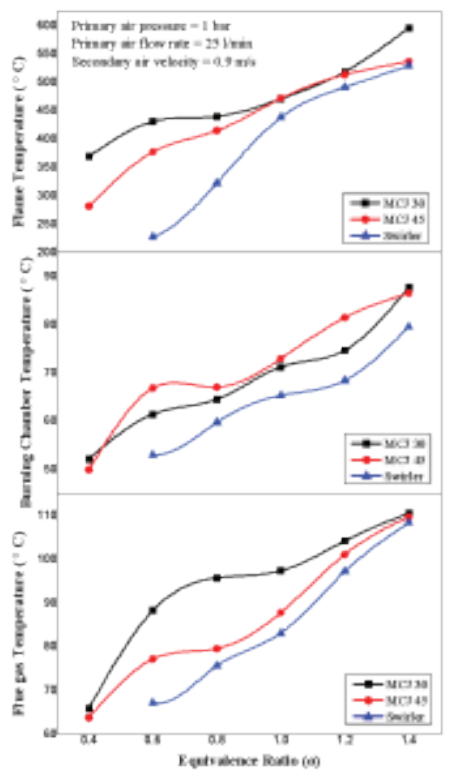

Fig. 7. Measured temperature of three plates at different equivalence ratio.

\section{Conclusion}

At the end of these investigations, the effects of geometrical conditions on the spray and combustion characteristics were determined. The following conclusions were derived.

1. Inclination of the jet plate at $30^{\circ}$ allows high mixture formation in the mixing chamber, leading to improved performance of the air-assisted atomizer compared with those of the plate inclined at $45^{\circ}$ and the swirler.

2. The inclined jet plate also contributes to flame stability during combustion.

3. The geometry of the turbulence generator in the atomizer should be considered in improving the efficiency of the burner system. 


\section{Acknowledgement}

The authors would like to thank the Ministry of Higher Education Malaysia for supporting this research under Fundamental Research Grant Scheme (FRGS) Vot 1492 and Centre for Graduate Studies UTHM.

\section{References}

1. M. Rashad, H. Yong, and Z. Zekun, Int. J. Hydrogen Energy, 41, 35, 15790-15799 (2016).

2. J. Jedelský and M. Jícha, Appl. Therm. Eng., 96, 286-296 (2016).

3. A. M. E. Faik and Y. Zhang, EPJ Web of Conferences, 92, 30-37 (2015).

4. M. Ochowiak, S. Rozanska, M. Matuszak, and S. Wlodarczak, Chem. Eng. Process. Process Intensi., 98, 52-59 (2015).

5. T. N. C. Anand, A. M. Mohan, and R. V. Ravikrishna, Fuel, 102, 613-623 (2012).

6. J.-K. Yeom and W.-S. Jung, Int. J. Precis. Eng. Manuf., 16, 7, 1279-1291 (2015).

7. A. Khalid, S. H. Amirnordin, L. Lambosi, B. Manshoor, M. F. Sies, and H. Salleh, Advanced Materials Research, 408, 1900-1911 (2013).

8. A. Khalid, L. Lambosi, M. Suardi, S. H. Amirnordin, I. Zaman, N. Mansor, and B. Manshoor, 774, 496-500 (2015).

9. A. Davanlou, J. D. Lee, S. Basu, and R. Kumar, Chem. Eng. Sci., 131, 243-255 (2015).

10. D. Sivakumar, S. K. Vankeswaram, R. Sakthikumar, B. N. Raghunandan, J. T. C. Hu, and A. K. Sinha, Fuel, 179, 36-44 (2016).

11. J. Jedelsky and M. Jicha, 23rd Annu. Conf. Liq. At. Spray Syst., 1-5 (2010).

12. S. S. Hou, C. Y. Lee, and T. H. Lin, Energy Convers. Manag., 48, 5, 1401-1410 (2007).

13. C. T. Chong and S. Hochgreb, Int. Biodeterior. Biodegrad., 102, 1, 353-360 (2015).

14. T. Sponfeldner, S. Henkel, N. Soulopoulos, and F. Beyrau, In European Combustion Meeting, 1-19 (2011).

15. M. F. Othman, B. Manshoor, and A. Khalid , IOP Conf. Ser. Mater. Sci. Eng., 50,1, 012050 (2013).

16. G. Coppola and A. Gomez, Exp. Therm. Fluid Sci., (33), 7, 1037-1048 (2009).

17. N. Soulopoulos, J. Kerl, F. Beyrau, Y. Hardalupas, and J. C. Vassilicos, Mech. Eng., $1-18$ (2010).

18. A. A. Verbeek, T. W. F. M. Bouten, G. G. M. Stoffels, B. J. Geurts, and T. H. van der Meer, Combust. Flame, 162, 1, 129-143 (2015).

19. R. Y. S. Chin, A. Khalid, A. M. A. Ghani, M. M. Issak, and S. H. Amirnordin, ARPN J. Eng. Appl. Sci., 11, 12, 7491-7497 (2016).

20. A. Abou El-Azm Aly, A. Chong, F. Nicolleau, and S. Beck, Exp. Therm. Fluid Sci., 34, 1, 104-111 (2010).

21. F. C. G. A. Nicolleau, S. M. M. Salim, and A. F. Nowakowski, J. Turb., 12, N44. 